\title{
Elites ministeriais e partidos políticos na transição democrática italiana
}

\author{
Ministerial elite and political parties \\ in Italian democratic transition
}

Goffredo Adinolfi

O objetivo deste artigo é analisar as relações entre partidos políticos e elites ministeriais numa transição democrática, como foi a italiana entre 1943 e 1948. Os resultados apresentados inscrevem-se num trabalho mais amplo de análise das elites políticas italianas no período que vai de 1921 - data das primeiras eleições realizadas com um sistema eleitoral proporcional e com sufrágio universal - até a consolidação da democracia a partir das eleições de 1953. Partindo da questão relativa aos modelos de recrutamento e às diferenças em relação ao período fascista anterior, a análise será desenvolvida levando em consideração

Goffredo Adinolfi é doutor em história contemporânea pela Universidade de Milão e pesquisador do Centro de Investigação e Estudos em Sociologia do Instituto Superior de Ciências do Trabalho e da Empresa (ISCTE) em Lisboa (goffredoadinolfi@hotmail.com).

Artigo recebido em 30 de junho e aprovado para publicação em 10 de agosto de 2008.

Estudos Históricos, Rio de Janeiro, vol. 21, nº 42, julho-dezembro de 2008, p. 145-171. 
sobretudo três vertentes: partidos, transição e elites. Esta última, todavia, será predominante, sendo nosso objetivo compreender o perfil social e político de quem, em 1943, teve que recolher o leme da condução do país. É por fim oportuno sublinhar que este artigo surge das questões deixadas sem resposta por um trabalho anterior (Adinolfi, 2007) que analisava de forma mais genérica as elites ministeriais italianas.

\section{Transição e elites na Itália (1943-1948)}

Haverá necessidade de mais um estudo sobre elites, transições, partidos e sistemas políticos? A literatura relativa a esses temas é de fato bastante ampla, ao passo que é mais reduzida a que põe no centro da sua abordagem a relação entre instituições e mudanças das elites políticas, ainda que, como lembra Pippa Norris, "as instituições [tenham] um papel fundamental no comportamento dos atores políticos" (Pippa Norris, 1997: 191). A temática das elites, central na nossa investigação, é mais desenvolvida no trabalho fundamental de Linz e Stepan (2005), centrado nas questões sobre quem começa as transições e por que a antiga elite não foi capaz de começar os processos de transição. Morlino (2003), por seu lado, concentra-se nas modalidades de legitimação da nova elite, num contexto onde não houve eleições, e salienta a questão que se tornará central no desenvolvimento do sistema político italiano, a saber: como se firmou a ancoragem dos partidos na sociedade civil italiana num contexto, o de 1943, em que a hipótese democrática estava longe de ser a mais consensual?

Nancy Bermeo também sustenta que a investigação deveria procurar perceber melhor a relação entre mudança de regime e mudança de elite: "na realidade, nós, enquanto cientistas políticos, temos estado preocupados com o que as elites fazem, mas temos dispensado pouco tempo a estudar quem são essas elites” (Bermeo, 2006: 232). Será oportuno, portanto, continuar no caminho trilhado por Robert Putnam quando, em seu célebre trabalho de 1976, lembrava que "as mudanças nas elites políticas proporcionam um diagnóstico fundamental das principais ondas da história" (Putnam, 1976: 52). Andrés Malamud salienta ainda a necessidade de novas abordagens e, no seu último trabalho (2008), analisa os vários contrastes na literatura relativa às transições, procurando realçar a falta de consenso entre os especialistas e desenvolvendo seu discurso a partir de um dos textos clássicos sobre a "transitologia": Transition from authoritarian rule (O’Donnell, Schmitter e Whitehead: 1986).

A literatura sobre o caso italiano parece merecer especial atenção e algumas "precauções", já que, paradoxalmente, é ao mesmo tempo a mais antiga e a mais incompleta. Os trabalhos de Maurizio Cotta $(1979,2000,2006)$, por exem- 
plo, deixam sem resposta uma questão fundamental: quem são as elites autoritárias? Normalmente, a questão dos partidos na transição italiana é despachada com alguma pressa, o que faz com que o período anterior às primeiras eleições políticas de 18 de abril 1948 ainda represente, com respeito a este assunto, um espaço aberto.

\section{Periodização}

O período que é aqui objeto de análise inscreve-se entre dois momentos marcantes para a história política italiana: 25 de julho 1943, data da aprovação da moção de desconfiança do Grande Conselho do Fascismo contra Benito Mussolini - a que se seguiu a formação de um novo governo liderado pelo general Pietro Badoglio - e 23 de maio 1948, dia em que o último governo de transição, de Alcide de Gasperi (o quarto), deu lugar ao primeiro governo constitucional, sempre chefiado por Alcide de Gasperi (o quinto).

Entre essas duas datas temos nove governos, sendo que a vigência de cada um (de duração sempre bastante curta) acaba por caracterizar um período específico no processo de transição:

1) 25 de julho de 1943 - 18 de junho de 1944: dois governos militares do general Pietro Badoglio, durante os quais a hipótese de uma reestruturação do regime fascista em torno da sua ala mais monárquica fracassa diante da incapacidade do governo de enfrentar as conseqüências da derrota militar (Perfetti, 2005).

2) 18 de junho de 1944 - 21 de junho de 1945: dois governos de Ivanoe Bonomi. As duas datas representam, respectivamente, a libertação ${ }^{1}$ de Roma e a libertação do país, ou, se quisermos, o fim da Segunda Guerra Mundial na Europa. O sistema político italiano, nessa altura, descarta a hipótese de um regime autoritário e procura recuperar as elites do período final do regime liberal (1870-1925), no qual Bonomi fora um vulto de primeira importância.

3) 21 de junho de 1945 - 10 de dezembro de 1945: governo liderado por Ferruccio Parri. Trata-se do governo mais progressista de todo o período, pois Parri, líder do Partito d'Azione (Partido de Ação, PdA), um dos líderes da luta de resistência italiana, era o símbolo de um país que queria promover uma profunda mudança nas suas estruturas dentro de um quadro delineado pelas democracias liberais. O PdA tinha suas raízes no pensamento do Rissorgimento italiano do século XIX, e suas idéias representavam sobretudo a burguesia progressista.

4) 10 de dezembro de 1945 - 2 de fevereiro de 1947: três governos de Unidade Nacional liderados por Alcide de Gasperi. Nesses dois anos se constrói o novo sistema político italiano: o referendo de 2 de junho 1946 transforma a Itá- 
lia numa República, enquanto, no mesmo dia, é também eleita a Assembléia Constituinte, sendo já nesse momento evidente a relevante maioria da Democrazia Cristiana (Democracia Cristã, DC) e, no campo das esquerdas, o substancial equilíbrio entre socialistas e comunistas.

5) 31 de maio de 1947 - 23 de maio de 1948: último governo do período de transição, De Gasperi IV, já fortemente marcado pelo clima de separação entre mundo ocidental e países do realismo socialista. Com efeito, o Partito Comunista Italiano (Partido Comunista Italiano, PCI) deixa de estar dentro da coligação governamental, na qual nunca mais poderá ingressar. As eleições de 18 de abril 1948 confirmam, mais uma vez, o papel fundamental da DC, mas também o papel de principal opositor do PCI, o que tornaria o sistema italiano um bipolarismo imperfeito (Galli), pois era inconcebível que um partido "anti-sistema" (Sartori, 1982) pudesse assumir a responsabilidade de formar um governo.

\section{Epílogo-prólogo: as elites ministeriais, primeiras conclusões}

Foi só a partir de 8 de setembro 1943 que os partidos puderam voltar a se reunir, e só a partir de abril de 1944 que se pôde constituir um governo inteiramente político, o de Ivanoe Bonomi. Começa então a fase dos governos dos $\mathrm{Co}$ mitati di Liberazione Nazionale (Comitês de Libertação Nacional, CLN), que vai durar até maio de 1947, período durante o qual é preciso reconstruir as instituições do país. As eleições realizadas a 2 de junho de 1946 para a Assembléia Constituinte e, conjuntamente, o referendo República/Monarquia constituem um momento de virada fundamental na vida política italiana. O sistema monárquico é preterido em benefício do sistema republicano, ao mesmo tempo que é delineada a real força dos partidos, o que leva, conseqüentemente, à definição dos novos equilíbrios.

Os resultados de um trabalho anterior sobre as elites ministeriais durante a transição (Adinolfi, 2007) - do qual, como acenamos, este artigo representa a continuação ideal - foram que, muito embora os ministros desse período tivessem, em sua grande maioria, um passado político no período liberal e fizessem parte da mesma geração dos ministros do período fascista, poucos deles tinham sido recrutados para cargos executivos nos governos que antecederam a instalação do regime fascista.

A marcar uma certa continuidade com o regime liberal, e, ao mesmo tempo, uma descontinuidade com o regime fascista, é possível definir quatro grandes variáveis: o aumento da taxa de portadores de diploma superior; o aumento da representação de professores universitários; o fim da participação de militares e a grande representação de ministros com um passado profissional na advocacia ou com uma licenciatura em direito. 
Em termos de continuidade com o fascismo e de descontinuidade com o regime liberal, temos a profissionalização da política, que se torna cada vez maior. Nesse sentido, evidencia-se que todos os partidos passam a assumir um modelo de recrutamento de ministros que começa por ter nos dirigentes partidários seu grupo de eleição, o qual se converte, com a criação da Assembléia Constituinte, no grupo dos deputados (parlamentarização do sistema político).

Ao longo dos cinco anos estudados, afirma-se assim a profissionalização da política. O recrutamento é feito dentro dos partidos de massa fortemente estruturados de cima para baixo, primeiro entre os dirigentes, depois nas Câmaras (nesse caso a Consulta Nacional e a Assembléia Constituinte). Os partidos de notáveis perdem uma guerra que tinha ficado aberta no momento do golpe de Estado de 1926, quando o governo fascista proibiu a atividade de todos os partidos políticos existentes, exceto o Partito Nazionale Fascista (Partido Nacional Fascista, PNF).

Essa trajetória vertical, que caracteriza a construção da democracia, é evidente na percentagem de ministros que eram deputados à Assembléia Constituinte, que no sétimo e no oitavo governo atinge $100 \%$. Nosso estudo anterior tinha todavia deixado aberta uma questão, qual seja, se as linhas gerais do modelo de recrutamento podiam ser aplicadas da mesma forma a todos os partidos, ou, ao contrário, se cada um deles declinava esse padrão segundo suas próprias exigências.

\section{Os partidos}

Escrever significa também escolher, entre muitas, uma estrutura que pareça satisfazer mais que outras as exigências de clareza e compreensibilidade do discurso. Aqui, decidimos analisar as variáveis por partido e, em cada partido, analisar três dimensões: a ideológica, a do peso no Executivo e a do perfil social dos ministros pertencentes ao partido. Por fim, tentaremos fornecer uma síntese conclusiva das principais linhas que emergiram deste estudo. Em relação à estrutura do artigo, decidimos abordar em primeiro lugar - tratando-se de um estudo específico sobre as elites ministeriais - os partidos que fizeram parte das coligações governamentais, e só em segundo os partidos que tiveram mais representatividade.

A idéia inicial é que, num regime incipiente, se assiste a um processo de forte oligarquização partidária. De fato, os partidos não eram ainda legitimados por eleições e muito menos por uma rede articulada de militantes. Nesse contexto, os partidos do período (1943-1948) existem somente no próprio núcleo dirigente em torno do qual se constroem as elites ministeriais, parlamentares e parti- 
dárias. Tentaremos, assim, analisar como os diferentes "modelos de partido" se refletem em diferentes modelos de recrutamento (Panebianco, 1984).

Tal como é evidenciado no gráfico 1, os partidos políticos desempenham um papel fundamental na escolha dos ministros somente a partir do segundo governo Badoglio (abril de 1944), mas é sobretudo a partir do terceiro governo da transição (Bonomi, junho de 1944) que os ministros não filiados a partidos deixam de ter qualquer papel na vida política do país, tanto que na linguagem jornalística o termo partitocracia virá a substituir democracia.

\section{GRÁFICO 1}

Clivagem entre ministros filiados a partidos e não filiados a partidos

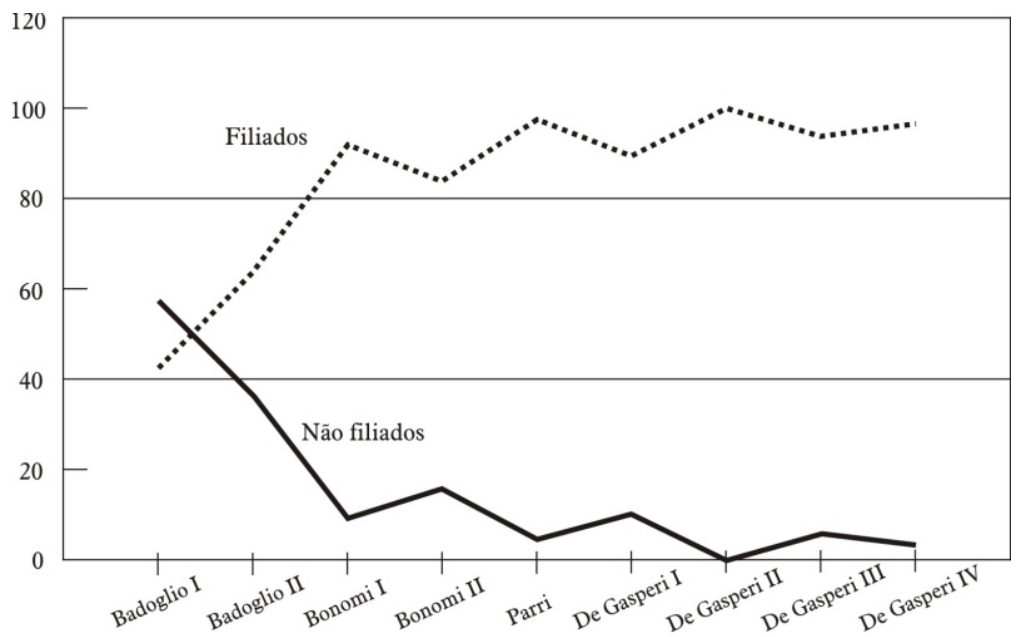

Dada a evidente clivagem entre a realidade do país e sua elite política, $o$ grau de representação sociológica não é objeto do nosso trabalho. Perceber quem governa e como se chega a governar, segundo o nosso ponto de vista, significa sobretudo analisar os perfis dos ministros por partido e verificar as diferenças nas modalidades de recrutamento.

Os partidos que governaram essa fase foram oito. Antes de mais nada temos a Democracia Cristã, que é de longe o partido com o maior peso, tendo 25,4\% dos ministérios distribuídos em todos os nove diferentes governos. Depois vem o Partito Socialista di Unità Proletária (Partido Socialista de Unidade Proletária, PSIUP), com 12,70\% dos ministérios e participação em oito dos nove governos então constituídos, sendo a exceção o primeiro governo de Badoglio. $\mathrm{O}$ PCI, por seu lado, está presente em sete dos nove governos, não estando representado no primeiro governo de Badoglio, nem no quarto governo de De Gasperi, com uma percentagem de $11,11 \%$ dos ministérios. O Partito Liberale Italiano 
(Partido Liberal Italiano, PLI) também tem um certo peso, com 10,58\% dos ministérios e uma participação em oito governos, ficando fora do terceiro governo de De Gasperi. Encontramos depois o PdA, o Partito della Democrazia del Lavoro (Partido da Democracia do Trabalho, DdL), o PNF e, por fim, o Partito Repubblicano Italiano (Partido Republicano Italiano, PRI) que teve, nessa fase, um papel muito marginal e portanto não será aqui objeto de análise.

Dez são as variáveis em torno das quais tentaremos reconstruir a elite política italiana, sendo possível resumi-las em três grandes categorias:

1) Relevância governamental: peso dos partidos no governo em termos de pastas, importância dessa presença com respeito ao relevo dessas pastas;

2) Passado político dos ministros: atividade política no regime liberal, atitude diante do fascismo e cargo exercido antes da nomeação, no período da ditadura;

3) Dados biográficos: lugar e data de nascimento, formação e profissão.

QUADRO 1

Peso dos partidos políticos nos diferentes ministérios (\%)

\begin{tabular}{lrrrrrrrrrr}
\hline & PCI & DC & PS & PdA & DL & PL & PNF & PRI & SF $^{\star}$ & $\%$ \\
\hline Badoglio I & - & 3,57 & - & - & - & 17,86 & 21,43 & - & 57,14 & 100 \\
Badoglio II & 10,53 & 5,26 & 15,79 & 15,79 & - & 15,79 & - & - & 36,84 & 100 \\
Bonomi I & 9,09 & 13,64 & 31,82 & 18,18 & 4,55 & 13,64 & - & - & 9,09 & 100 \\
Bonomi II & 21,05 & 15,79 & 21,05 & - & 15,79 & 10,53 & - & - & 15,79 & 100 \\
Parri & 14,29 & 19,05 & 19,05 & 23,81 & 9,52 & 9,52 & - & - & 4,76 & 100 \\
De Gasperi I & 15,00 & 25,00 & 15,00 & 10,00 & 10,00 & 10,00 & - & 5,00 & 10,00 & 100 \\
De Gasperi II & 20,00 & 50,00 & 20,00 & - & - & 5,00 & - & 5,00 & - & 100 \\
De Gasperi III & 18,75 & 43,75 & 18,75 & 6,25 & 6,25 & - & - & - & 6,25 & 100 \\
De Gasperi IV & - & 60,87 & 13,04 & 4,35 & - & 8,70 & - & 8,70 & 4,35 & 100 \\
\hline
\end{tabular}

^ Sem filiação

\section{Partito Nazionale Fascista (PNF)}

Sendo impossível reconstruir os passos do PNF ao longo dos cerca de 20 anos de ditadura, o que importa sublinhar aqui é que, após a aprovação da moção de desconfiança a Benito Mussolini pelo Grande Conselho do Fascismo (entre 24 e 25 de julho de 1943), o quadro político era ainda muito fluido. A nomeação do general Pietro Badoglio, militar próximo da coroa mas também figura de relevo no regime fascista, não foi, de maneira alguma, um primeiro passo no sentido 
da democracia, pois a questão fundamental não era acabar com a ditadura, e sim encontrar uma forma de sair de uma guerra que já estava perdida, com os exércitos inimigos entrando pelo sul do país e, portanto, de remover o principal obstáculo ao armistício, que era o próprio Duce.

QUADRO 2

Peso dos partidos políticos no governo, número de ministérios e número de ministros

\begin{tabular}{lcc|cc}
\hline & Ministérios & $\%$ & Ministros & $\%$ \\
\hline PCI & 21 & 11,11 & 6 & 6,25 \\
DC & 48 & 25,40 & 21 & 21,88 \\
PSIUP & 24 & 12,70 & 12 & 12,50 \\
PdA & 16 & 8,47 & 10 & 10,42 \\
DL & 16 & 8,47 & 4 & 4,17 \\
PL & 20 & 10,58 & 14 & 14,58 \\
PNF & 7 & 3,70 & 6 & 6,25 \\
PRI & 4 & 2,12 & 3 & 3,13 \\
Sem filiação & 33 & 17,46 & 20 & 20,83 \\
Total & 189 & 100 & 96 & 100 \\
\hline
\end{tabular}

A presença de ministros com passado no regime fascista limitou-se, porém, ao primeiro governo Badoglio (julho de 1943 - fevereiro de 1944, quadro 1), e foi também nesse ano que o projeto de uma recomposição do regime fascista em torno dos hierarcas mais próximos da monarquia fracassou. Mas o peso dos ministros fascistas dentro do primeiro governo que se seguiu à ditadura foi forte, e o próprio presidente do Conselho, Badoglio, ainda que não fosse um fascista tout court, tinha sido chefe das forças armadas durante o fascismo até 1941, quando a entrada da Itália na guerra, ao lado da Alemanha e contra a Inglaterra e a França, o afastou definitivamente do Duce. Assim, ex-fascistas chegaram a ter pastas importantes no primeiro governo Badoglio: Interior e Negócios Estrangeiros, Finanças e Guerra (quadro 3).

Naufragado o projeto dos hierarcas que aprovaram a moção de desconfiança contra Mussolini a 25 de julho de 1943, naufragou também a possibilidade de um futuro para os militantes fascistas, que, como demonstram os dados, durante os governos da transição foram excluídos dos postos executivos. O que é preciso salientar é que, e em coerência com outros estudos efetuados (Adinolfi, 2004, 2008), os ministros fascistas do primeiro governo Badoglio também não tinham desempenhado papéis no regime liberal anterior (quadro 5), representando por- 
QUADRO 3

Peso dos partidos políticos nos diferentes ministérios (\%)

\begin{tabular}{|c|c|c|c|c|c|c|c|c|c|c|}
\hline & PCI & DC & PS & PdA & DL & PL & PNF & PRI & $\mathrm{SF}^{\star}$ & $\%$ \\
\hline $\begin{array}{l}\text { Presidente do } \\
\text { Conselho }\end{array}$ & - & 44,44 & - & 11,11 & 22,22 & - & - & - & 22,22 & 100 \\
\hline Interior & - & 36,63 & - & 9,09 & 18,18 & 9,09 & 18,18 & - & 9,09 & 100 \\
\hline $\begin{array}{l}\text { Negócios } \\
\text { Estrangeiros }\end{array}$ & - & 33,33 & 11,11 & 22,22 & 11,11 & - & 11,11 & - & 11,11 & 100 \\
\hline Justiça & 40,00 & 20,00 & - & - & - & 20,00 & - & - & 20,00 & 100 \\
\hline Agricultura & 50,00 & 30,00 & - & - & - & 10,00 & 10,00 & - & - & 100 \\
\hline Comércio Estrangeiro & - & 75,00 & - & - & - & - & - & 25,00 & - & 100 \\
\hline Finanças & 44,44 & 22,22 & - & 11,11 & - & 11,11 & 11,11 & - & - & 100 \\
\hline Guerra & - & 12,50 & - & - & - & 37,50 & 12,50 & 12,50 & 25,00 & 100 \\
\hline Indústria & - & 45,45 & 36,36 & - & - & 9,09 & - & - & 9,09 & 100 \\
\hline Obras Públicas & 10,00 & 20,00 & 30,00 & 10,00 & 10,00 & 20,00 & - & - & - & 100 \\
\hline Trabalho & - & 20,00 & 80,00 & - & - & - & - & - & - & 100 \\
\hline Marinha & - & 14,29 & - & - & - & - & - & - & 85,71 & 100 \\
\hline $\begin{array}{l}\text { Correios e } \\
\text { Telecomunicações }\end{array}$ & - & 57,14 & 28,57 & - & 14,29 & - & - & - & - & 100 \\
\hline Instrução Pública & - & 30,00 & 10,00 & 20,00 & - & 30,00 & - & - & 10,00 & 100 \\
\hline Tesouro & - & 33,33 & - & - & - & 33,33 & - & - & 33,33 & 100 \\
\hline Transportes & 33,33 & 16,67 & 16,67 & 33,33 & - & - & - & - & - & 100 \\
\hline
\end{tabular}

* Sem filiação

QUADRO 4

Cargo exercido antes de ser nomeado ministro (\%)

\begin{tabular}{lccccccccc}
\hline & PCI & DC & Psiup & PdA & DL & PL & PNF & PRI & SF* $^{\star}$ \\
\hline Dirigente partidário & 16,67 & 15,79 & 40,00 & 25,00 & - & - & - & - & 7,14 \\
Consulta Nacional & - & - & - & - & - & - & - & 33,33 & - \\
Assembléia & 33,33 & 42,11 & 20,00 & - & - & - & - & 33,33 & - \\
Constituinte & - & - & - & - & - & - & - & - & - \\
Deputado & - & - & - & 50,00 & 33,33 & 28,57 & 100 & - & 64,29 \\
Nenhum & 16,67 & 31,58 & 20,00 & - & - & 57,14 & - & - & 21,43 \\
Subsecretário & 100 & 100 & 100 & 100 & 100 & 100 & 100 & 100 & 100 \\
& & & & & & & & & \\
\hline
\end{tabular}

* Sem filiação 
tanto o fascismo um verdadeiro "corte" ou um parêntese no processo de desenvolvimento que, da Itália liberal, vai até a Itália republicana. O fato de eles serem, em $66 \%$ dos casos, do sul, e em 33\%, do centro do país sugere que, provavelmente, não eram fascistas de "primeira hora" - sendo o fascismo um fenômeno originário do norte -, e sim mais ligados a um fascismo caciquista que aceitou do fascismo sobretudo a possibilidade de controlar o poder (quadro 7). Não estaríamos por outro lado diante de um patamar certo de recrutamento (quadro 8). Com respeito à idade, $50 \%$ deles tinham mais de 60 anos, embora houvesse uma minoria (16\%) com menos de 50 (quadro 9).

QUADRO 5

Carreira política durante o regime liberal até 1924 (\%)

\begin{tabular}{lccccccccc}
\hline & PCI & DC & Psiup & PdA & DL & PL & PNF & PRI & SF` $^{\star}$ \\
\hline Dirigente partidário & 50,00 & 19,05 & 33,33 & - & - & - & - & - & - \\
Deputado & 16,67 & 28,57 & 50,00 & 10,00 & 25,00 & 14,29 & - & 33,33 & - \\
Ministro & - & 19,05 & - & 10,00 & 50,00 & 14,29 & - & - & 10,00 \\
Sem cargos & 33,33 & 33,33 & 16,67 & 80,00 & 25,00 & 71,43 & 100 & 66,67 & 90,00 \\
Total & 100 & 100 & 100 & 100 & 100 & 100 & 100 & 100 & 100 \\
\hline
\end{tabular}

* Sem filiação

QUADRO 6

Atividade política durante o regime fascista (1925-1943) (\%)

\begin{tabular}{lccccccccc}
\hline & PCI & DC & Psiup & PdA & DL & PL & PNF & PRI & SF` $^{\star}$ \\
\hline Sem resposta & - & - & 8,33 & - & - & - & - & - & 9,00 \\
Sem carreira prévia & - & 14,58 & - & 6,25 & 18,75 & 15,00 & - & - & 6,00 \\
Sem atividade politica & - & 58,33 & 33,33 & 6,25 & 81,25 & 80,00 & - & 25,00 & 76,00 \\
Preso & 66,67 & 27,08 & 33,33 & 18,75 & - & 5,00 & - & - & - \\
Exilado & 33,33 & - & 25,00 & 37,50 & - & - & - & 75,00 & 3 \\
Fascista & - & - & - & - & - & - & 100 & - & 3 \\
Resistência & - & - & - & 31,25 & - & - & - & - & 3 \\
\hline
\end{tabular}

* Sem filiação

QUADRO 7

Clivagem norte-sul (\%)

\begin{tabular}{lccccccccc}
\hline & PCI & DC & Psiup & PdA & DL & PL & PNF & PRI & SF* $^{\star}$ \\
\hline Noroeste & 33,33 & 28,57 & 50,00 & 10,00 & 50,00 & 28,57 & - & - & 35,00 \\
Nordeste & 33,33 & 19,05 & - & - & 50,00 & - & - & - & 5,00 \\
Centro & 16,67 & 33,33 & 8,33 & 20,00 & - & 7,14 & 33,33 & 100 & 10,00 \\
Preso & 16,67 & 19,05 & 41,67 & 70,00 & - & 64,29 & 66,67 & - & 20,00 \\
\hline
\end{tabular}

* Sem filiação 
QUADRO 8

Clivagem cidade-campo (\%)

\begin{tabular}{lccccccccc}
\hline & PCI & DC & Psiup & PdA & DL & PL & PNF & PRI & SF $^{\star}$ \\
\hline Sem resposta & - & - & - & - & - & - & - & - & 30,00 \\
$<40.000$ hab. & 16,67 & 38,10 & 41,67 & 40,00 & 25,00 & 21,43 & 33,33 & 33,33 & 30,00 \\
40.000-100.000 hab. & 33,33 & 23,81 & 16,67 & - & 25,00 & 42,86 & 16,67 & 66,67 & 10,00 \\
100.000-300.000 hab. & 16,67 & 14,29 & 8,33 & 20,00 & 50,00 & 21,43 & - & - & 5,00 \\
$>300.000$ hab. & 16,67 & 4,76 & 8,33 & 20,00 & - & 14,29 & 33,33 & - & 15,00 \\
Milão & - & 9,52 & 16,67 & - & - & - & - & - & 10,00 \\
Roma & 16,67 & 9,52 & 8,33 & 20,00 & - & - & 16,67 & - & - \\
\hline
\end{tabular}

* Sem filiação

QUADRO 9

Idade

\begin{tabular}{lccccccccc}
\hline & PCI & DC & Psiup & PdA & DL & PL & PNF & PRI & SF $^{\star}$ \\
\hline$<30$ & - & - & - & - & - & - & - & - & - \\
$30-39$ & 33,33 & 4,76 & - & - & - & - & - & - & - \\
$40-49$ & 16,67 & 28,57 & 33,33 & 30,00 & - & 35,71 & 16,67 & 66,67 & 15,00 \\
$50-59$ & 50,00 & 38,10 & 41,67 & 50,00 & 25,00 & 14,29 & 33,33 & 33,33 & 25,00 \\
$>60$ & & 28,57 & 25,00 & 20,00 & 75,00 & 50,00 & 50,00 & - & 35,00 \\
\hline
\end{tabular}

* Sem filiação

QUADRO 10

Formação (\%)

\begin{tabular}{lccccccccc}
\hline & PCI & DC & Psiup & PdA & DL & PL & PNF & PRI & SF $^{\star}$ \\
\hline Sem diploma superior & - & 4,76 & 25,00 & 10,00 & - & 28,57 & 16,67 & 33,33 & 5,00 \\
Educação militar & - & - & - & - & - & - & 16,67 & - & 35,00 \\
Agronomia e veterinária & 16,67 & - & - & - & - & - & 25,00 & - & - \\
Economia & 16,67 & 15,00 & 11,11 & - & - & - & - & - & 8,33 \\
Engenharia & 16,67 & 5,00 & 22,22 & 11,11 & - & 10,00 & - & - & - \\
Letras e ciências sociais & - & 10,00 & - & 33,33 & - & 10,00 & - & - & - \\
Direito & 50,00 & 60,00 & 44,44 & 44,44 & 100 & 80,00 & 75,00 & 100 & 50,00 \\
Química e física & - & 5,00 & - & - & - & - & - & - & - \\
\hline
\end{tabular}

* Sem filiação 
Com base nos dados relativos à formação (quadro 10) e às profissões (quadro 11), podemos sublinhar que os ministros em análise eram da facção "menos revolucionária": $80 \%$ deles eram licenciados em direito e só 16\% eram políticos profissionais, sendo os restantes mais ou menos igualmente distribuídos entre professores universitários, militares, diplomatas e prefeitos.

QUADRO 11

Profissão exercida antes da primeira nomeação (\%)

\begin{tabular}{lccccccccc}
\hline & PCI & DC & Psiup & PdA & DL & PL & PNF & PRI & SF \\
\hline Outras profissões & - & 9,52 & - & - & - & - & - & - & - \\
Advogados & - & - & - & 10,00 & - & 7,14 & - & - & - \\
Juízes & 16,67 & 23,81 & 33,33 & 10,00 & 50,00 & 50,00 & - & 33,33 & - \\
Professores & - & - & - & - & - & - & - & - & 15,00 \\
Professores & - & - & - & 10,00 & - & - & - & - & - \\
universitários & 16,67 & 23,81 & 8,33 & 20,00 & - & 21,43 & 16,67 & 33,33 & 5,00 \\
Servidores públicos & & & & & & & & & \\
graduados & - & 4,76 & - & - & - & - & 16,67 & - & 5,00 \\
Militares & - & - & - & - & - & - & 16,67 & - & 35,00 \\
Jornalistas & - & 4,76 & - & 20,00 & - & - & - & 33,33 & - \\
Engenheiros & 16,67 & 4,76 & 8,33 & 10,00 & - & - & - & - & - \\
Funcionários & - & 4,76 & - & 10,00 & - & 7,14 & - & - & 5,00 \\
Diplomatas & - & - & - & 10,00 & - & - & 33,33 & - & 5,00 \\
Empresários & - & - & - & - & - & 7,14 & - & - & 5,00 \\
Economistas & - & 4,76 & 8,33 & - & - & - & - & - & - \\
Políticos profissionais & 50,00 & 19,05 & 41,67 & - & 50,00 & 7,14 & 16,67 & - & - \\
\hline
\end{tabular}

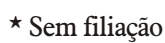

\section{Democrazia Cristiana (DC)}

A DC foi o partido que dominou o horizonte político durante todo o pós-guerra italiano, até a crise que abalou o sistema entre 1992 e 1994. Tinha como "núcleo duro" os dirigentes do antigo Partito Popolare (Partido Popular, $\mathrm{PP}$ ), embora entre as duas formações não existisse nenhuma real continuidade política.

Apesar de contar com uma forte organização - associações católicas, sindicatos, bancos e jornais -, bem como com um considerável apoio eleitoral nas penúltimas eleições livres antes do regime fascista se instalar em 1922 (20\%), o 
PP dissolveu-se logo em 1925, depois de ter feito parte do primeiro governo de coligação de Mussolini (1922-1925). A maioria dos seus dirigentes voltou ao desempenho das profissões anteriores (Galli, 1978), com exceção do grupo dos chamados neoguelfi, liderado por Piero Malvestiti, que enveredou por um caminho de oposição aberta ao regime.

Os primeiros passos da antiga classe dirigente no sentido de regressar à política ativa foram dados, a partir de 1942, em reuniões informais em torno do novo secretário geral Alcide de Gasperi, que pôde contar, desde logo, com o apoio da Confindustria, uma associação que reunia (e reúne) os empresários italianos e se tornaria a maior financiadora da DC, estabelecendo-se uma forte ligação entre as duas organizações (Panebianco, 1984).

Foram três os principais grupos na origem do primeiro núcleo da DC, que formariam as chamadas correnti, ou seja, verdadeiros partidos dentro do partido dominante: os neoguelfi, que militaram no antifascismo; os membros da Ação Católica, que guardaram do fascismo a idéia do corporativismo e de uma democracia relativamente restrita, cujos modelos podiam ser encontrados no salazarismo, mas também em vultos como Dolfuss ou Robbles, e ainda o grupo dos "intelectuais" que se formaram na Universidade Católica, como Giulio Andreotti, Aldo Moro e Emílio Colombo.

A consolidação da DC enquanto partido só ocorreu depois de 25 de abril de 1945, quando a Igreja percebeu que o futuro da Itália estava na incorporação do modelo das democracias que tinham contribuído para a libertação do país. Até essa data, a história da DC foi a história dos seus dirigentes reunidos em Roma (Galli, 1978), e foi exatamente em torno dos que integravam o Executivo que se formou o partido, que, dadas essas circunstâncias, nasceu necessariamente como um partido de governo. Estruturou-se dessa forma uma hierarquia que partia dos ministros, passava pelos parlamentares e, em último lugar, atingia o partido (Panebianco, 1984). Construiu-se assim uma formação política baseada numa rede de notáveis locais cujo controle escapava aos dirigentes nacionais, os quais acabaram por preferir evitar o desenvolvimento do partido no território. Verificaram-se com efeito dois processos de desenvolvimento relativamente autônomos um do outro: a formação da classe dirigente e o enraizamento nas estruturas locais.

Os dados mostram-nos que, desde os primeiros passos no sentido da democratização do sistema político italiano, a DC ocupou um espaço predominante (quadro 2). O grupo de ministros associados ao partido é, sem dúvida, o maior entre os dos vários partidos representados, compreendendo 21 pessoas, ou seja $21,9 \%$ do total dos ministros. ${ }^{2}$ Além disso, também o próprio peso dos ministérios ocupados por homens da DC era absolutamente fundamental (quadro 3). Alcide de Gasperi, secretário geral da DC, liderou quatro dos nove governos des- 
se período, ou seja, foi primeiro- ministro em $44 \%$ dos casos. O Ministério dos Negócios Estrangeiros, verdadeiro posto-chave para um país sob ocupação militar, foi chefiado em 33\% dos casos pela DC, e o Ministério do Interior, em 36\% dos casos. A partir dessa plataforma, a DC viria a construir a sua longa hegemonia.

Quanto à parlamentarização do sistema político italiano-e à construção de uma elite política em torno do grupo parlamentar (Cotta, 2006) -, podemos verificar que na DC havia uma hierarquia e algumas etapas fundamentais que antecediam o percurso de chegada às pastas ministeriais (quadro 4). Em mais de $42 \%$ dos casos, antes da nomeação, os ministros haviam sido deputados à Assembléia Constituinte, em 31\% subsecretários, em 15\% dirigentes partidários (sobretudo antes da eleição da Assembléia Constituinte) e, por fim, 10\% deles tinham experiência nos governos do período liberal. Para resumir, nenhum dos ministros da DC exerceu o cargo de ministro sem antes percorrer algumas etapas da carreira política.

Trata-se de uma experiência amadurecida durante um passado político relativamente longínquo, pois só em 33\% dos casos os ministros da DC não tinham tido nenhum cargo político no regime liberal (quadro 5), enquanto, por outro lado, não foram poucos os ministros ocupando os cargos de deputado (28,6\%) ou até de ministro (19\%) antes da virada totalitária em janeiro de 1925.

Os dados relativos à atividade política durante a ditadura (quadro 6) vêm confirmar o que a literatura já tinha afirmado relativamente aos militantes do PP-DC: em 58\% dos casos, não se registra atividade política durante esse período, embora haja um número relativamente baixo de ministros que, na vigência do regime, foram julgados por crimes políticos (apenas um, ou seja 4,8\% dos casos). ${ }^{3}$ Por outro lado, nenhum deles aderiu à resistência, mas também nenhum teve ligações com o regime fascista.

Sobretudo devido a uma falta de profissionalização política, que ainda caracterizava a época pré-fascista, $71,4 \%$ dos ministros da DC dos governos da transição tinham decidido, com o advento de Mussolini, não continuar as atividades políticas iniciadas no período liberal e voltar, durante o fascismo, às suas profissões privadas. Portanto, podemos concluir que ser antifascista era uma mais-valia, embora não fosse absolutamente fundamental para obter o cargo de ministro. Mas com certeza ter aderido ao regime fascista era uma condição que impedia a subida ao topo do partido.

Tentaremos agora perceber quais são os principais traços biográficos dentro do partido. No que diz respeito às variáveis geográficas (cidade-campo, norte-sul), podemos salientar que a maioria dos ministros $(38,1 \%)$ pertencia à primeira faixa do quadro 8 e $23 \%$ pertenciam à segunda, e que Milão e Roma não eram os principais centros de recrutamento (apenas 9,5\% nos dois casos). Esses 
dois fatores permitem pensar que o recrutamento foi relativamente difuso, embora com alguma exceção, nas cidades pequenas. Quase metade dos ministros (49\%) era enfim oriunda do norte do país e apenas 19\% vinham do sul (quadro 7).

Quanto à idade (quadro 8), constata-se que $38 \%$ dos ministros tinham entre 50 e 59 anos no momento da sua nomeação e que $28,6 \%$ tinham mais de 60 anos, um dado importante porque evidencia o baixo nível de mudança nas elites políticas, sendo mais uma contraprova da longa tradição dessa formação. Apenas $4,8 \%$ dos ministros tinham menos de 40 anos e, portanto, não haviam conhecido o regime liberal anterior.

Com respeito à variável formação (quadro 10), 90,5\% dos ministros da DC tinham grau superior, sendo que a absoluta maioria havia passado pela Faculdade de Direito (60\%), seguida pelas de Economia (15\%) e de Letras $(10 \%)$.

A DC poderia ser definida como um partido de advogados e professores universitários (quadro 11), os quais tinham um peso de $23,81 \%$ cada, o que, no total, representava quase metade da composição ministerial. Os políticos profissionais no momento da nomeação correspondiam a $19,05 \%$ do total dos ministros do partido, um valor relativamente baixo, que confirma o outro dado, relativo à atividade política durante o regime fascista. Enfim, se excluirmos essas três profissões - advocacia, ensino universitário e carreira propriamente política - não havia outras que emergissem com um certo relevo.

\section{Partito Comunista Italiano (PCI)}

O PCI foi o único partido que manteve a sua organização ativa ao longo de todo o regime fascista. A sua estrutura bolchevista, baseada em células secretas, permitiu-1he sobreviver na clandestinidade durante mais de 20 anos. Calcula-se que em março de 1943, quando foi proclamada uma grande greve no norte de Itália, o número de militantes estivesse na ordem das 5.000 pessoas. Era um partido legitimado no exterior (Panebianco, 1984), pois nasceu na seqüência da Revolução Soviética e estava subordinado ao Partido Comunista Soviético, muito embora a sua organização tivesse sofrido profundas modificações no pós-guerra. Nesse contexto, foi-se estruturando como um partido social-democrata, afastando-se, portanto, da vertente marxista-leninista e passando a se estruturar quer em organizações formadas no interior das empresas, quer em células locais (Tarrow, 1972). Nesse sentido, no panorama dos partidos comunistas representou uma verdadeira exceção: se Sartori (1982) classifica o PCI como um partido "anti-sistema", outros politólogos, como Farneti (1975), mostram como os dois grandes partidos de massas (DC e PCI) sempre pactuaram as reformas. 
Não se tratava só de um partido formado em torno de um núcleo de revolucionários profissionais. Era também um partido de massas, muito embora a sua matriz inicial tenha continuado a influenciar o seu modelo de funcionamento (Colarizi, 1997).

Trata-se de um partido fortemente centralizado, cujas elites dirigentes se tinham formado no quadro da III Internacional (Galli, 2001). Nesse sentido, a existência de diferentes correntes de opinião era proibida estatutariamente (centralismo democrático). Contrariamente à DC, que se desenvolveu em torno dos ministros/dirigentes, o PCI era por natureza um partido de oposição, totalmente estruturado a partir dos seus dirigentes, aos quais os ministros e os parlamentares estavam subordinados. Palmiro Togliatti, líder carismático e secretário geral do PCI até sua morte em 1964, tinha a percepção de que na Itália uma revolução era simplesmente impossível. Assim, estabeleceu uma estratégia que se pode designar "em dois tempos". Num primeiro momento, o objetivo era ampliar os espaços da democracia, e só num segundo momento poder-se-ia levar à frente a revolução. Esta era, no fundo, a idéia gramsciana da conquista da hegemonia cultural e política. De fato, nessa fase, toda a política de Togliatti baseava-se na idéia de que a Itália era, por definição, um país moderado, dentro do qual era impossível governar sem ter o apoio da Igreja católica.

O grupo de ministros do PCI foi, ao contrário do da DC, muito reduzido (quadro 2), sendo apenas 6 os ministros que participaram dos governos da transição, sem que houvesse, por outro lado, uma rotatividade: ao mudarem os governos, os ministros eram sempre os mesmos. Esse dado é aliás normal se pensarmos que, para o PCI, a participação no governo representava uma atividade quase secundária, pois o papel mais importante era dentro e através do próprio partido.

O peso do PCI nos governos da transição foi bem menor em comparação com o que teve a DC (quadro 3), em primeiro lugar porque nunca ocupou a presidência do Conselho, e em segundo lugar pela importância dos ministérios. Duas foram as pastas nas quais o PCI desempenhou um papel mais importante: Justiça (ministério que, em $40 \%$ dos casos, foi o próprio Togliatti quem chefiou) e Finanças $(44,4 \%)$. No total dos nove governos que caracterizaram o período da transição, apenas $11 \%$ dos ministros foram do PCI, que assim se coloca em terceiro lugar, depois da DC e do PSIUP.

No que diz respeito ao passado político dos ministros comunistas, o perfil é bastante peculiar: ainda que apenas 33\% não tivessem experiência política, nenhum deles foi ministro nos governos do período liberal (quadro 5) e apenas $16,7 \%$ foram deputados, enquanto em $50 \%$ dos casos foram dirigentes partidários. Os dados não devem surpreender, sendo que as primeiras eleições às quais o PCI 
concorreu, logo depois da sua criação, foram as de 1921.

A componente antifascista dentro do grupo de ministros do PCI era de $100 \%$ (quadro 6): $66 \%$ estiveram na prisão e $33 \%$ foram exilados. Nenhum deles deixou de ter atividade política durante os anos do fascismo. Essa variável nos vem confirmar a continuidade do PCI antes e depois do fascismo.

Ao traçar as biografias do grupo de ministros do PCI, constata-se em primeiro lugar (quadro 7) que os ministros originários do centro e do sul da Itália eram muito menos numerosos (16,7\% em ambos os casos) do que os que provinham do noroeste e nordeste (33,3\% em ambos os casos). A elite ministerial comunista era fortemente urbanizada (quadro 8), sendo em 33,3\% dos casos oriunda de cidades com um número de habitantes que variava entre entre 40 e $100 \mathrm{mil}$, em $16,7 \%$ dos casos de cidades que possuíam entre 100 e 300 mil habitantes e em $16,7 \%$ dos casos de cidades com mais de 300 mil. Somente em 16,7\% dos casos os ministros eram originários de cidades com menos de 40 mil habitantes.

Contrariamente ao que se observa em relação aos outros partidos, nos quais é evidente a variação na faixa etária, no PCI a maioria dos ministros (quadro 9) - ou seja, 33,3\% - tinha menos de 40 anos: isso significa que se formaram nos anos do regime fascista e que pouco conheceram do passado liberal. A metade dos ministros (50\%) estava na quarta faixa, entre os 50 e os 59 anos, e apenas $16,7 \%$ entre 40 e 49.

Verifica-se também que $100 \%$ dos ministros do PCI tinham formação superior (quadro 10): $50 \%$ em direito, 16,7\% em economia, agronomia e engenharia, o que representa a maior taxa de diplomados entre todos os partidos do período da transição.

Ao chegarmos à variável profissão (quadro 11), não deve surpreender a alta taxa de profissionalização política dos ministros do PCI (50\%), pois já vimos como eles tinham continuado sua atividade política durante o fascismo. No que diz respeito às outras profissões, não estamos diante de grandes linhas de recrutamento, pois os advogados, os engenheiros e os professores universitários estavam igualmente representados em $16,7 \%$ dos casos.

Como conclusão, portanto, podemos afirmar que o modelo de recrutamento do PCI demonstra o caráter extremamente compacto do seu núcleo dirigente, o que determinava a existência de uma grande estabilidade nos critérios de escolha.

\section{Partito Socialista di Unità Proletária (PSIUP)}

O Partido Socialista, ou PSIUP, voltou a nascer entre 1942 e 1943 depois de ter sido completamente desarticulado pelas estruturas repressivas do regime 
fascista no princípio da década de 1930. Após as eleições de 1921, as últimas realmente livres antes da ditadura, o PSIUP era o maior partido da Itália, com $24 \%$ dos votos. Nele reuniam-se principalmente três almas: o antigo núcleo dirigente socialista, o grupo do Movimento de Unidade Proletária (MUP) - militantes que agiam na clandestinidade no norte do país -, e um terceiro grupo que se formou dentro dos Grupos Universitários Fascistas (GUF).

Uma outra clivagem era representada pela separação existente entre os militantes exilados e os que permaneceram na Itália. Em termos gerais, constata-se que o PSIUP herdou do antigo PS da época liberal uma estrutura fortemente conflituosa que se dividia entre maximalistas, reformistas e fusionistas (com o PCI), ou seja, entre elementos da direita, do centro e da esquerda (Colarizi, 1997). Herdou também do passado uma classe dirigente composta de notáveis e uma forte parlamentarização do partido (Panebianco, 1984).

O conflito interno do Partido Socialista refletia-se numa alta rotatividade, como evidencia o fato de que nas 24 pastas (quadro 2) geridas por membros do PSIUP nos nove governos da transição alternaram-se 12 diferentes ministros. $\mathrm{O}$ peso eleitoral do pré-guerra refletia-se também na amplitude do grupo socialista no Executivo, pois, em percentual, o partido colocava-se logo depois da DC, constituindo o segundo maior grupo. Se o PSIUP era o segundo partido com maior representação dentro do governo, isso não significa que a quantidade correspondesse à qualidade (quadro 3), inferida pelo peso dos ministérios controlados. As pastas nas quais dominaram os socialistas eram as de caráter econômico: as do Trabalho (80\%), de Obras Públicas (30\%) e da Indústria (36\%). Apenas em 11\% dos casos a pasta dos Negócios Estrangeiros foi socialista.

Se formos observar o cargo exercido antes da nomeação, verificaremos que nenhum dos ministros ligados ao PSIUP tinha tido qualquer cargo político anterior (quadro 4): $40 \%$ deles haviam sido dirigentes partidários, enquanto os deputados à Assembléia Constituinte e os subsecretários representavam cerca de $20 \%$ dos casos.

Fortes eram também os laços do PSIUP com o regime liberal anterior (quadro 5), pois 50\% dos ministros já tinham sido deputados na Câmara, e 33\%, dirigentes partidários. Apenas 16\% não haviam tido nenhum cargo nas fases finais do liberalismo monárquico.

Mais difícil foi encontrar dados biográficos relativos à atividade política exercida durante a ditadura. Em 8,33\% dos casos não temos qualquer informação (quadro 6). Podemos todavia afirmar que em $58 \%$ dos casos os ministros tiveram uma postura ativa contra o regime: $25 \%$ foram exilados e $33 \%$ passaram pelas prisões. Particularmente elevado é o número dos ministros que durante o regime não tiveram nenhuma atividade política (33\%). 
A origem geográfica dos ministros socialistas é bastante polarizada: $50 \%$ nasceram no noroeste (quadro 7), 41,6\% no sul e apenas $8,3 \%$ no centro do país. Tal como no caso da DC, embora com menos freqüência, $41 \%$ dos ministros provinham de cidades com menos de 40 mil habitantes (quadro 8). Em cerca de $25 \%$ dos casos os ministros eram oriundos de cidades entre 40 e 300 mil habitantes (segunda e terceira faixas) e 16,7\% provinham de Milão, a cidade que até os anos 60 do século passado constituiu a capital do socialismo italiano.

A estrutura etária (quadro 9) dos ministros vem confirmar a idéia de um núcleo dirigente relativamente velho, muito voltado para o regime liberal anterior: em $25 \%$ dos casos os ministros tinham mais de 60 anos, enquanto $41,6 \%$ tinham entre 50 e 59, 33\% entre 40 e 49 e nenhum tinha menos de 40.

Relativamente à formação (quadro 10), o grupo de ministros do Partido Socialista era o que tinha menor percentagem de diplomados (75\%), depois dos republicanos e dos liberais. Mais uma vez foi a Faculdade de Direito que formou a maior parte das elites ministeriais, com $44,4 \%$ dos casos, enquanto as menos representadas foram as de Engenharia (22,22\%) e de Economia (11,11\%).

Para $41,67 \%$ dos ministros socialistas a profissão dominante era a carreira política (quadro 11), seguida pela advocacia (33,3\%). Professores universitários, engenheiros e economistas representavam, por seu lado, $8,33 \%$ dos casos.

\section{Partito Liberale Italiano (PLI)}

O Partido Liberal foi o partido dominante no período anterior ao regime fascista, e a força mais prejudicada pelo nascimento dos partidos de massas, entre as décadas de de 1910 e 1920 . Ainda na época liberal, a estrutura do partido era muito fraca, tratando-se basicamente de um partido de notáveis. Foi justamente a incapacidade de atualizar o partido em face das novas realidades sociais surgidas do pós-guerra que provocou sua marginalização no sistema político. De caráter predominantemente conservador, o PL não conseguiu porém se tornar uma referência para os eleitores no campo da direita, que, num primeiro momento, votaram em forças não leais à nova ordem, como os partidos monárquicos ou o Uomo Qualunque, para depois se deixarem atrair pelo anticomunismo da DC.

Trata-se de um grupo relativamente pouco numeroso (quadro 2), que constituiu o quarto partido com maior peso dentro dos nove governos da transição democrática, pois $10 \%$ das pastas foram lideradas por ministros liberais. Porém, a escassa importância das pastas revela a decadência do partido, que, após ocupar brevemente, logo após a aprovação da moção de desconfiança contra 
Mussolini, lugares importantes (quadro 3), logo passou a desempenhar papéis secundários. As percentagens do período estão assim distribuídas: $10 \%$ no Ministério do Interior, 37,5 \% na pasta da Guerra e 30\% na Instrução Pública (foi o caso do importante filósofo Benedetto Croce, que durante todo o regime fascista exerceu uma atividade de forte oposição moral). Além disso, é também importante salientar que o partido nunca voltou a chefiar um governo.

O escasso peso dos ministros liberais na primeira fase da transição é também revelado pela ausência de ministros com background na Assembléia Constituinte, que só foi eleita em junho de 1946 (quadro 4): antes da nomeação, em sua maioria (57\%) os ministros eram subsecretários, e em $28 \%$ dos casos não tinham tido nenhum outro cargo político de relevo.

Paradoxalmente, embora o PLI tivesse tido um papel fundamental no período liberal (quadro 5), 71,43\% dos ministros liberais da transição não exerceram cargo político naquela época, apenas $14 \%$ foram ministros e $14 \%$ deputados. Enfim, apenas em 5\% dos casos o grupo de ministros liberais sofreu a repressão política do regime fascista (quadro 6).

No que diz respeito à naturalidade, quase $64,29 \%$ dos ministros liberais nasceram no sul da Itália (quadro 7 ) e $28,57 \%$ no noroeste. Apenas $21 \%$ deles eram oriundos de cidades com menos de 40 mil habitantes, sendo mais de $60 \%$ pertencentes à segunda e à terceira faixas, entre 40 e 300 mil habitantes (quadro 8). Poderia ser definido como um partido de cidades de média dimensão, pois também não existe uma representação significativa das grandes cidades.

Outro paradoxo é que num partido de notáveis o peso dos diplomados fosse relativamente baixo (quadro 10): apenas $71,3 \%$ dos ministros tinham formação superior e, entre estes, cerca de $80 \%$ eram formados em direito, tendo o mesmo peso (10\%) as formações em engenharia e letras.

Verifica-se também que 7,2\% dos indivíduos considerados pertenciam à categoria de políticos profissionais (quadro 11), o dado mais baixo entre os partidos. Enfim, a profissão mais comum era a advocacia, com $50 \%$ dos casos, seguida pelo ensino universitário (21\%).

\section{Partito d'Azione (PdA)}

O Partito d'Azione nasceu da e na luta antifascista, formado por quadros que na maioria dos casos tinham lutado contra os alemães no norte da Itália, ou tinham como elemento unificador a luta antifascista, como os membros do grupo Giustizia e Libertà. O partido nasceu da convergência de três origens ideológicas diferentes: o socialismo, o liberalismo e o republicanismo. Nesse sentido, era um partido muito pouco coeso, com uma fraca implantação territorial. Essas são 
as razões da sua brevíssima existência e do fato de que, apesar do seu fortíssimo peso moral, nas primeiras eleições de 2 de junho de 1946 foi completamente derrotado.

Os dados relativos ao peso do PdA nos governos da transição são extremamente contraditórios, pois as grandes expectativas do partido de se tornar um dos pilares fundamentais da recém-constituída República foram frustradas (quadro 2). No cômputo geral, foi o quinto partido com maior peso quantitativo, mas, se formos verificar a importância da sua participação de um ponto de vista qualitativo (quadro 3), veremos que, com a DC e o DdL, foi o único partido a chefiar um governo. E mais, 20\% dos ministros dos Negócios Estrangeiros e 10\% dos ministros do Interior foram do PdA. Enfim, em 1947, o partido dissolveu-se devido aos contínuos conflitos.

O PdA poderia ser também definido com um "partido novo", pois em $50 \%$ dos casos não foram detectados cargos políticos anteriores (quadro 4), e em $25 \%$ o único cargo político exercido foi o de dirigente partidário. Talvez essa escassa ancoragem nas instituições e na sociedade civil tenha decretado a sua morte prematura.

O PdA é o emblema do partido antifascista (quadro 6), mas contrariamente ao PCI, nele há uma fusão entre luta de resistência e governo, pois $31,25 \%$ dos ministros desse grupo combateram com as armas o nazi-fascismo. Trata-se também de um partido de ex-exilados (37,50\%) - outro provável fator de falta de raízes na sociedade italiana - e de ex-presos políticos (18,75\%), enquanto apenas em $6,25 \%$ dos casos não se registra atividade política prévia.

O caráter de novidade é demonstrado também pelas escassíssimas ligações com o antigo passado liberal (quadro 5): $80 \%$ dos ministros não ocuparam cargo político nesse período, $10 \%$ foram deputados e outros $10 \%$ foram ministros.

Por ser um partido cuja origem remontava às lutas de resistência no norte do país, é paradoxal o fato de seus ministros provirem sobretudo do sul (quadro 7), o que se verifica em $70 \%$ dos casos, contra apenas $10 \%$ em que a naturalidade é do noroeste. Dos ministros azionisti, $40 \%$ nasceram em cidades com menos de 40 mil habitantes (quadro 8), e $40 \%$ em cidades com mais de 100 mil, o que parece ser bastante dicotômico, mas mais uma vez isso vem revelar o caráter do PdA, extremamente fragmentário e de escassa implantação na sociedade.

Trata-se também de um partido relativamente jovem (quadro 9), pois os maiores de 60 anos são apenas $20 \%$, embora não haja ministros com menos de 40 , a maioria deles concentrando-se na faixa entre 50 e 60 (50\%), contando-se também $30 \%$ entre 40 e 50 anos.

O PdA apresenta uma taxa de diplomados (quadro 10) de $88 \%$, e entre todos os partidos tem a maior presença de formados em letras (33,3\%), embora os 
formados em direito sejam, como sempre, mais numerosos $(44,4 \%)$; por fim temos $11,1 \%$ de formados em engenharia.

No que diz respeito à atividade profissional (quadro 11) exercida antes da nomeação, podemos dizer que não há um padrão de recrutamento, mas o que importa observar, em coerência com todos os dados até aqui apresentados relativamente ao $\mathrm{PdA}$, é que não há políticos profissionais. Os grupos dos jornalistas e dos professores universitários representam cada um $20 \%$, sendo também baixa a presença de advogados, com apenas $10 \%$, e relativamente alta, em comparação com outros partidos, a de diplomatas (10\%).

\section{Partito della Democrazia del Lavoro (DdL)}

Falaremos nesta última parte do Partito della Democrazia del Lavoro (Partido da Democracia do Trabalho, DL), liderado por Ivanoe Bonomi, figura de proa do período liberal, com um passado de militância no Partido Socialista. A guerra colonial contra a Líbia (1912) e, ainda mais, a Primeira Guerra Mundial (1914-1918), vieram a afastar definitivamente Bonomi do PS e torná-lo um líder político mais moderado. Em 1916 foi ministro do Trabalho no governo Boselli e, entre 1921 e 1922, foi presidente do Conselho, ministro do Interior e dos Negócios Estrangeiros. Durante os anos do regime fascista voltou à profissão de advogado, não exercendo nenhuma atividade política. A importância política de Bonomi decorreu das suas capacidades diplomáticas. Logo depois dos governos militares de Badoglio, foi nomeado pelo rei presidente do Conselho, no primeiro governo pluripartidário pós-fascista. As suas origens de esquerda o tornavam um candidato aceitável, e o seu filomonarquismo fazia com que não fosse malvisto pela direita política. Todavia, o DL não chegou a se apresentar às eleições para a Assembléia Constituinte de 1946. Em 1947 Bonomi se tornaria presidente do Partito Socialista Democrático Italiano (Partido Socialista Democrático Italiano, PSDI), constituído naquele mesmo ano.

A escolha de Ivanoe Bonomi para o terceiro e quarto governos da transição, de junho de 1944 até junho de 1945 (fim da guerra e "libertação" do nazi-fascismo) é fortemente simbólica, pois esses governos representam, em nosso entender, os últimos da Itália liberal.

Nesse momento de clivagem, o peso de Bonomi, ou, se quisermos, do seu partido, o DdL, foi bastante importante, sobretudo por sua participação qualitativa (quadro 3), com $22 \%$ dos presidentes do Conselho, $18 \%$ dos ministros do Interior, 33\% da Defesa e 11\% dos Negócios Estrangeiros. Isto é, o DdL monopolizou a saída do fascismo num momento em que a hegemonia da DC ainda não estava firmada. 
Trata-se de um partido mais voltado para o passado (quadro 5), como demonstra o fato de que, entre os seus ministros, $50 \%$ já tinham ocupado aquele cargo e $25 \%$ o de deputado durante o liberalismo, sendo, pelo contrário, praticamente nula a atividade política durante o pós-guerra (quadro 4). Mas era também um partido muito moderado, que durante o regime fascista preferiu deixar a atividade política em $80 \%$ dos casos (quadro 6).

$\mathrm{O}$ centro de recrutamento era no norte do país (quadro 7), entre cidades de pequena e média dimensão, com respectivamente $25 \%$ e $75 \%$ (quadro 8 , segunda e terceira faixas). Trata-se enfim de um grupo muito mais velho do que os outros partidos (quadro 9), com $25 \%$ dos casos situando-se entre 50 e 59 anos e os restantes $75 \%$ tendo mais de 60 anos. A formação única era em direito (quadro 10), tal como a profissão única era a advocacia (quadro 11).

\section{Conclusões}

Os dados que analisamos nestas páginas nos deram respostas bastante interessantes. Em primeiro lugar, podemos afirmar que cada partido tem um modelo de recrutamento bastante específico. Se a DC é o partido que mais representação tem nos pequenos centros, o PCI é, pelo contrário, aquele tem maior representação nas grandes cidades. Se o PdA é o partido do sul, o Partido Comunista é o partido do norte.

Quanto à profissionalização da política, essa variável atinge o seu ponto mais alto no PCI, o que aliás não é uma grande surpresa, e tem o seu valor mais baixo nos dois partidos que maior implantação tinham tido no período liberal, PSIUP e PLI, provavelmente devido a uma forma de entender a política muito diferente daquela que veio a formar-se durante o período do regime fascista e no período da democracia republicana do pós-guerra. O PdA é o partido do emprego público: professores universitários e funcionários de alto nível, enquanto o PLI pode ser definido como o partido das profissões privadas.

Também no que diz respeito ao antifascismo temos modelos bastante polarizados. Por um lado, a DC e o PLI, que apresentam a percentagem mais baixa de ministros com posições antifascistas, e por outro, o PCI e PdA, cuja totalidade dos ministros sofreu exílio ou prisão durante o regime, tendo sido, portanto, claramente seus opositores.

Dos sete partidos que participaram dos governos da transição, só três foram protagonistas - a DC, o PSIUP e o PCI -, enquanto três desapareceram PNF, DdL e PdA - e um sobreviveu, deixando seu lugar de partido predominante - PLI. O percurso da transição não nos parece ter sido um percurso inevi- 
tável da ditadura para uma democracia parlamentar e republicana. Aliás, pelo contrário, podemos constatar, com a evidência dos dados, como, logo a seguir ao afastamento de Mussolini, os ex-militantes do banido PNF continuaram a desempenhar um papel de grande relevância. Passado um ano, no verão de 1944, o sistema político italiano tentou recuperar a elite do período liberal: o projeto de uma restauração autoritária foi descartado e abriu-se o período dos governos de Bonomi. Seguiu-se o governo de Ferruccio Parri, líder da resistência, talvez o mais determinado no processo de "depuração" da antiga elite. Por fim, o novo fulcro do equilíbrio foi encontrado na Democracia Cristã, que desde logo se afirmou como o partido central do sistema político.

As eleições de 18 de abril de 1948 determinaram no campo das esquerdas a hegemonia do Partido Comunista, deixando o Partido Socialista em posição subalterna. A DC veio assim a ocupar o centro do sistema político e tornou-se o partido imprescindível para qualquer coligação governamental até abril de 1994. Esse fenômeno foi a base de uma fragmentação lenta, mas constante, no quadro partidário italiano, que, devido a uma falta de alternativas, levou a uma profunda crise do sistemaa partir dos anos 1970. Mas a pergunta verdadeira, que aqui não conseguimos responder é: por que o PSIUP não conseguiu legitimar-se como fulcro principal de uma oposição capaz de disputar o governo com a DC? Talvez seja a procura da resposta a essa pergunta um caminho importante para as próximas investigações, pois, num nível teórico, assim como demonstramos neste trabalho, o PSIUP tinha todos os pressupostos para ser uma das duas principais forças políticas italianas, e aliás era visto como tal pelas elites da época. Ao afastamento do PCI do nono governo da transição, devido seja à conjuntura internacional, seja às posições anti-sistema desse partido, não correspondeu o afastamento do PSIUP, que continuou a fazer parte da coligação com a DC.

Notas

1. Para que se possa entender melhor o uso do substantivo "libertação", convém explicar que até 8 de setembro 1943 metade da Itália estava ocupada por forças inimigas (a coligação anglo-americana) e metade estava sob o controle dos alemães, chamados pelo governo italiano (ainda chefiado por Benito Mussolini) para fazer frente àquela ocupação. Após 8 de setembro 1943, data em que foi proclamado o armistício, esse axioma inverteu-se: os alemães tornaram-se a força invasora, enquanto o exército 
anglo-americano, ou os "Aliados", passou a ser uma força de libertação militar e política do nazi-fascismo.

2. Logo após a DC, o partido mais representado, com $14,58 \%$ dos ministros, é o Partido Liberal.

3. Infelizmente, nem sempre os dados quantitativos são os mais adequados para

Referências bibliográficas

ADINOLFI, G. 2004. The fascist ministerial elite (1922-1943). Portuguese Fournal of Social Science, Bristol, vol. 3, $\mathrm{n}^{\mathrm{o}} 2$.

2007. As elites ministeriais no processo da transição democrática italiana. Seminários de investigação Portugal Contemporâneo: Política e Relações Internacionais, 19 de maio.

- 2008. A elite fascista: o Grão Conselho do Fascismo e os ministros (1922-1943). Congresso da Associação Portuguesa de Ciência Política, 6 e 7 de março.

BERMEO, Nancy. 2006. Conclusões. In: ALMEIDA, Pedro Tavares de, PINTO, António Costa \& BERMEO, Nancy (orgs.). Quem governa a Europa do Sul? Lisboa: Imprensa de Ciências Sociais.

BLONDEL, J. \& COTTA, M. 2000. The nature of party government: $a$ comparative European perspective. Hampshire: Palgrave Macmillan.

BOBBIO, Norberto. 2007. Dal fascismo alla democrazia. I regimi, le ideologie, le figure e le culture politiche. Milão: Baldini Castoldi Dalai. revelar verdades importantes, como, em relação a este assunto, o fato de que o único caso de um ministro da DC que foi julgado por crimes políticos durante o fascismo diz respeito ao próprio Alcide De Gasperi, que, depois de ter sido preso, viveu exilado no Estado do Vaticano.

COLARIZI, S. 1997. Storia dei partiti nell'Italia Repubblicana. Bari: Laterza.

COTTA, M. 1979. Classe politica e parlamento in Itália 1946-1976. Bolonha: Il Mulino.

COTTA, M. \& VERZICHELLI, L. 2006. Os ministros em Itália: notavi, dirigentes partidários, tecnocratas e homens dos media. In: ALMEIDA, Pedro Tavares de, PINTO, António Costa \& BERMEO, Nancy (orgs.). Quem governa a Europa do Sul? Lisboa: Imprensa de Ciências Sociais.

FARNETI, P. 1975. Il sistema politico italiano. Bolonha: Il Mulino.

GALLI, G. 1978. Storia della Democrazia Cristiana. Bari: Laterza.

. 2001. I partiti politici italiani (19432004). Milão: Rizzoli.

LAMPEDUSA, T. 1959. Il Gattopardo. Milão: Feltrinelli.

LINZ, J. J., e STEPAN, A. 2005. Transizione e consolidamento democratico. Bolonha: Il Mulino.

MALAMUD, Andrés \& BARAHONA, Alexandra. 2008. Dimensões internacionais da democratização: 
debates, paradoxos e opções políticas. IV Clóquio da Associação Portuguesa de Ciência Politica, Fundação Gulbenkian, 6 e 7 de março.

MORLINO, L. 1998. Democracy between consolidation and crisis : parties, groups, and citizens in Southern Europe. Oxford: Oxford University Press. 2003. Democrazie e democratizzazioni. Bolonha: Il Mulino.

NORRIS, Pippa (org.). 1997. Passages to power: legislative recruitment in advanced democracies. Cambridge: Cambridge University Press, p. 184-215.

O'DONNELL, Guillermo, SCHMITTER, Philippe C. \& WHITEHEAD, Laurence (orgs.). 1986. Transitions from authoritarian rule. Baltimore: Johns Hopkins University Press. 4 vols.

PANEBIANCO, A. 1984. Modelli di partito, organizzazione e potere nei partiti politici. Bolonha: Il Mulino.
PASQUINO, G. 1998. The demise of the first fascist regime and Italy's transition to democracy: 1943-1948. In: LARSEN, S. Modern Europe after fascism (1943-1980s). Boulder, Social Science Monographs, p. 45-70.

PERFETTI, F. 2005. Prefazione. In: GRANDI, D. La fine del regime. Florença: Le Lettere.

PUTNAM, R. D. 1976. The comparative study of political elites. New Jersey: Prentice Hall.

SARTORI, G. 1982. Teoria dei partiti e caso italiano. Milão: SugarCo.

SCOPPOLA, P. 1997. La repubblica dei partiti, evoluzione e crisi di un sistema politico (1945-1996). Bolonha: Il Mulino.

TARROW, S. 1972. Partito comunista e contadini nel Mezzogiorno. Torino: Einaudi.

\section{Resumo}

$\mathrm{O}$ artigo analisa as relações entre partidos políticos e elites ministeriais na transição democrática italiana ocorrida entre 1943, ano em que foi aprovada a moção de desconfiança do Grande Conselho do Fascismo contra Benito Mussolini, e 1948, ano em que teve início o primeiro governo constitucional. Nesse período sucederam-se nove governos, conviveram oito partidos, e assistiu-se a uma profissionalização da política. A partir dos dados apresentados em uma série de 11 quadros, são analisadas para cada partido três dimensões: a ideológica, a de seu peso no Executivo e a do perfil social dos ministros filiados.

Palavras-chave: elites políticas, recrutamento ministerial, profissionalização política

\section{Abstract}

The article is about the relationship between political parties and minesterial elite during the Italian democratic transition that took place between 1943, when the Great Council of Fascism voted for the resignation of Benito Mussolini, and 1948, when the first constitutional government took office. In 
this period Italy knew nine administrations and eight political parties, and politics became increasingly professional. A series of tables allows us to analyze the parties as to their ideology and their relevance in different administrations, and also to draw the social profile of their ministers. Keywords: political elite, ministerial recruitment, professional politics

Résumé

Larticle décrit les rapports entre les partis politiques et l'élite ministérielle pendant la transition démocratique italienne qui a eu lieu entre 1943, quand le Grand Conseil du Fascisme a voté pour la renonciation de Benito Mussolini, et 1948, quand le premier gouvernement constitutionnel a été investi. Dans cette période, l'Italie a connu neuf gouvernements et huit partis, et la politique est devenue professionnelle. Une série de 11 tableaux nous permet d'analyser les partis sous trois aspects: leur idéologie, leur poids dans les gouvernements, et le profil social des ministres qui leur étaient affiliés.

Mots-clés: élite politique, recrutement ministériel, politique profession politique 